\title{
Influence addition of Fine Sawdust on the Physical Properties of Expansive Soil in the Middle Nile Delta, Egypt
}

\author{
A. A. Abd El Halim ${ }^{1 *}$ and A.A. El Baroudy ${ }^{1}$ \\ ${ }^{I}$ Department of Soil and Water, Faculty of Agriculture, Tanta University, 31527 Tanta, Egypt. "Corresponding author: prof. \\ dr.abdelhalim@gmail.com
}

\begin{abstract}
This study evaluated how the fresh fine sawdust from Pinewood affects some hydro-physical properties of expansive soil which collected from the middle Nile Delta, Egypt. To fulfil this objective, a number of laboratory tests were carried on the clay loam soil samples collected from the depth of 0-30 cm. Clay loam soils were treated by sawdust at the rate of $0 \%, 1 \%, 2 \%, 5 \%, 10 \%, 15 \%$ and $20 \%$ on the dry weight basis. Various experimental methods were used to determine the variations in the falling-head permeability, the clay size fraction, the plasticity index, the linear shrinkage and the cracking width with different sawdust-amended soils. The results showed that the addition of sawdust decreases the clay size fraction, the plasticity index, the linear shrinkage and the cracking width, while it increases significantly the falling-head permeability, which is a sign improvement of soil hydro-physical properties. It can be concluded that sawdust had the potential to improve the hydro-physical properties of expansive soils, especially, when added into soil in between one to two percent on dry weight basis, above this percentage the improvement was much less significant and warranted by the clay content decrease.
\end{abstract}

Keywords: Sawdust, hydro-physical properties, soil consistency, soil shrinkage, soil cracks

\section{Introduction}

Nile Delta is the largest and most important depositional complex in the Mediterranean basin. Furthermore, it is the unique site in Egypt for accumulation and preservation of the Quaternary sediments. Expansive soils are ranging from clayey to silt clay and widely distributed in the northern and central parts of the Nile Delta (Moustafa, 2000).

Expansive soils are those whose volume change takes place while it meets water. Expansive soils owe their characteristics to the presence of swelling clay minerals. Therefore, the expansive soils have several major problems e.g. large volume changes; high water retention capacities; compaction under heavy tillage machinery; great stickiness, plasticity and limited moisture range during which they can't be satisfactory tilled and the high power requirement needed to plough them; crusting and cracking that adversely affect root penetration and seedling emergence and low rate of infiltration. 
These problems adversely affect most of the physical and hydraulic properties, in addition, nutritional status of such soils (Shaaban and Okasha, 2007).

Wood industry wastes of sawdust, bark, wood shavings, wood chips and finely divided wood fibbers have very few profitable uses. In Egypt, fine sawdust is considered as one of agricultural wastes, obtained from a lumber sawmills, and till now, has not been used in the other products. A continuous removal of such wastes from the production sites to be transformed into effective and low price soil amendments has become necessary.

Agricultural scientists have been reluctant to accept sawdust as a desirable form of organic matter to use as a mulch or soil amendment because of some of the problems it presents when added to the soil. Its slow rate of decomposition, which may or may not be a disadvantage, and its temporary depression of nitrates have been the principal objections to its use. The very low value of sawdust as a source of readily available plant nutrients is a recognized disadvantage. However, in spite of these disadvantages, the benefits that are being derived from the use of these wood wastes in improving the hydro-physical properties of the soil for certain plants can not be overlooked. As reported in previous literature the use of sawdust receiving increased interest, especially to improve the hydro-physical properties of soils (e.g., Chiroma et al., 2006; Edward, 2008; Eusufzai et al., 2007; Eusufzai and Fujii, 2012; Manukaji, 2013; Rajor et al., 1996). Applying sawdust to expansive soils may be a good way to help in solving the hydro-physical problems, but limited research has been done to quantify the beneficial effect of applying fresh fine sawdust to expansive soils.

Therefore, the aim of this study is to determine best addition of fresh fine sawdust to improve hydrophysical properties of expansive soils, and evaluate its effects on these properties.

\section{Materials and Methods}

\subsection{Study area}

Soil samples were selected from Kafr Masoud, a village lies about $10 \mathrm{~km}$ near of Tanta city in the middle Nile Delta of Egypt (30 $79^{\circ} 0$ " N, 30 $30^{\circ} 9^{\prime} 0$ ” E, $22 \mathrm{~m}$ a.s.1.) during 2012/2013. The soil of the studied area is characterized by a clay loam texture. The soil was classified as a Vertic Torrifluvents with the thermic soil temperature regime and torric soil moisture regime (El Baroudy, 2011). Primary physical properties of study soil are shown in Table 1. The annual mean temperature reaches its maximum in August exceeding $32.9^{\circ} \mathrm{C}$ and its minimum in December at $15.0^{\circ} \mathrm{C}$. The precipitation is not equally distributed in the study area over the rainy season. The amount of annual rainfall is very low and mostly falls in the winter reaching about $5 \mathrm{~mm}$ year ${ }^{-1}$ with the maximum falling in winter. Mean annual evapotranspiration reaches its maximum in August at $6.8 \mathrm{~mm} \mathrm{day}^{-1}$ (Rice research and training centre, Sakha station data).

\subsection{Fresh fine sawdust}

Fresh fine sawdust from Pinewood was used as an additive in the experimental procedure. The fine sawdust was obtained locally by collecting from sawmills, and then passed through a 1-mm sieve (ASTM No.18), finally, stored in an airtight containers to avoid pre-hydration until usage.

\subsection{Preparation of soil-fresh fine sawdust mixtures}

The samples were collected on September 2012 from top soil layer $(0-30 \mathrm{~cm})$ using the Standard Practice for Soil Investigation and Sampling by Auger Borings D1452-80 (ASTM, 2000) for disturbed soil samples, and then air-dried, crashed, and sieved through a 2-mm sieve (ASTM No.10) prior to usage. The soil and fresh fine sawdust were blended to prepare soil/sawdust mixtures (sawdust-amended soil treatments) under the dry conditions. The amounts of fresh fine sawdust were selected to be $1 \%, 2 \%, 5 \%, 10 \%, 15 \%, 20 \%$, and $0 \%$ 
(the control, non-amended soil, treatment) on the soil dry weight basis. All mixtures were done manually and proper care was taken to prepare homogeneous mixtures at each stage.

Table 1. Primary physical properties of the study soil

\begin{tabular}{|c|c|c|c|c|c|c|c|c|}
\hline \multicolumn{4}{|c|}{ Particle size distribution } & $\mathrm{BD}$ & $\mathrm{K}_{\mathrm{s}}$ & PI & LS & \multirow{2}{*}{$\begin{array}{l}\mathrm{CW} \\
\mathrm{mm}\end{array}$} \\
\hline $\begin{array}{c}\text { Sand } \\
<. .\end{array}$ & $\begin{array}{c}\text { Silt } \\
\ldots(\%) .\end{array}$ & $\begin{array}{l}\text { Clay } \\
. .>\end{array}$ & Textural class & $\mathrm{g} \mathrm{cm}^{-3}$ & $\mathrm{~cm} \mathrm{~h}^{-1}$ & \multicolumn{2}{|c|}{$<\ldots \ldots(\%) \ldots \ldots>>$} & \\
\hline 25 & 37 & 38 & Clay loam & 1.10 & 0.69 & 32.60 & 22.13 & 3.00 \\
\hline
\end{tabular}

$\widehat{\mathrm{BD}}$, Bulk density; $\mathrm{K}_{\mathrm{s}}$, Saturated hydraulic conductivity; PI, Plasticity index; LS, Linear shrinkage; CW, Crack width

\subsection{Laboratory analyses}

Falling-head permeability tests

The falling-head permeability tests were conducted to obtain saturated hydraulic conductivity $\left(\mathrm{K}_{\mathrm{s}}\right)$ values. These tests were performed according to Klute method which described by Bashour and Sayegh (2007). The samples were placed inside a cylindrical mould (102 $\mathrm{mm}$ in diameter and $117 \mathrm{~mm}$ in length) and water allowed to flow through the samples. The test apparatus consists of a mould with lids and a standpipe $10 \mathrm{~mm}$ in diameter and $100 \mathrm{~mm}$ in length. At least three samples were tested for each combination of saturated hydraulic conductivity values in permeability tests. The process was replicated three times and the $\mathrm{K}_{\mathrm{s}}$ for each replication were calculated from the following equation:

$$
\mathrm{K}_{\mathrm{s}}=(\mathrm{a} \times \mathrm{L} / \mathrm{A} \times \mathrm{t}) \ln \left(\mathrm{h}_{\mathrm{o}} / \mathrm{h}_{\mathrm{t}}\right)
$$

Where, the $\mathrm{K}_{\mathrm{s}}$ is the coefficient of permeability $(\mathrm{cm}$ $\left.\mathrm{sec}^{-1}\right)$, a is the area of burette standpipe $\left(\mathrm{cm}^{2}\right), \mathrm{L}$ is the length of the specimen $(\mathrm{cm}), \mathrm{A}$ is the area of specimen $\left(\mathrm{cm}^{2}\right), t$ is the elapsed time of the test ( $\left.\mathrm{sec}\right), \mathrm{h}_{\mathrm{o}}$ is the head at beginning (time $=0$ ) of the test $(\mathrm{cm})$ and $h_{t}$ is the head at the end $($ time $=t)$ of test $(\mathrm{cm})$.

\subsection{Clay size fraction (C) and plasticity index (PI)}

Clay size fraction $(\mathrm{C}$, material finer than $2 \mu \mathrm{m})$ was performed by the pipette method (Haluschack, 2006). Liquid limit, plastic limit and plasticity index (PI) were performed by the standard methods described as outlined in the American Society for Testing and Materials (ASTM) D4318-05 (ASTM, 2005).

\subsection{Linear Shrinkage tests $\left(L_{d}\right)$}

Linear shrinkage (LS) tests were conducted using approximately one hundred and fifty grams of the natural soil sample or soil-sawdust mixtures. The natural soil sample or soil-sawdust mixtures were transferred to glass plate and then water added and mixed thoroughly with two palette knives until the mass became a smooth thick homogenous paste with moisture content at about the liquid limit. The homogenous paste was placed in an airtight container and allows standing for 24 hours to enable the water to penetrate through the sample. A third of the prepared sample was placed in a greased aluminium mould approximately $140 \mathrm{~mm}$ long and $25 \mathrm{~mm}$ in diameter. The prepared sample was placed in the mould in three layers and tapped against a flat surface in between the layering to remove air bubbles from the sample. 
The sample was allowed to air dry for four hours. Then the sample was placed in an oven at $105{ }^{\circ} \mathrm{C}$ for 18 hours. After the sample was dry, the mould was removed from the oven, and then allowed to cool. The process was replicated five times and the length of the soil sample was measured with digital callipers and the average was used to calculate linear shrinkage using the following equation:

$$
\mathrm{LS}=\left[1-\left(\mathrm{L}_{\text {avg }} / \mathrm{L}_{\mathrm{o}}\right)\right] \times 100
$$

Where, LS is the linear shrinkage (\%), $\mathrm{L}_{\text {avg }}$ is the average length $(\mathrm{mm})$, and $\mathrm{L}_{\mathrm{o}}$ is the original length of aluminium mould (mm).

\subsection{Cracking width tests $(\mathrm{CW})$}

The development of desiccation cracks in the laboratory prepared samples representing natural soil sample and soil- sawdust mixtures was observed by cracking tests. The cracking tests were carried out in falling-head permeability test apparatus under hydrostatic pressure to get maximum saturation of the samples. All samples in cylindrical moulds were placed in inside fallinghead permeability test apparatus and water allowed to flow through the samples. In this stage, the samples were kept in laboratory conditions for $48 \mathrm{~h}$ to allow saturation of samples. At the end of $48 \mathrm{~h}$, saturated samples were extruded from the cylindrical moulds. These samples were kept under laboratory conditions for 28 days to allow for their desiccation and the development of desiccation cracks was observed on the surface of samples. The process was replicated five times and the width of cracks $(\mathrm{CW})$ were measured using digital callipers (resolution: $0.01 \mathrm{~mm}$ ) at ten points and the average was used.

\subsection{Statistical analysis}

The data were analyzed statistically using MSTATC ${ }^{\mathrm{TM}}$ version 2.0. Two-way ANOVA was used to determine statistically significant difference in all parameters among the tested samples. The significant differences between means were tested using Duncan's Multiple Range Test (DMRT) at the 5\% level.

\section{Results and Discussion}

\subsection{Effects of sawdust on saturated hydraulic conductivity}

The effects of sawdust (SD) on saturated hydraulic conductivity $\left(\mathrm{K}_{\mathrm{s}}\right)$ are shown in Figure 1. The saturated hydraulic conductivity $\left(\mathrm{K}_{\mathrm{s}}\right)$ values highly increased with increasing additions of the SD. The high values reached in the composite samples containing $15 \%$ and $20 \%$ SD-amended soil. The statistical analysis showed that no significant differences between the $1 \%$ and $2 \%$ SD-amended soil treatments, and the non-amended soil treatment. Similarly, no significant differences were found between the $15 \%$ and $20 \%$ SD-amended soil treatments (Figure 1). However, the 1\% and 2\% SDamended soil increased the $\mathrm{K}_{\mathrm{s}}$ by about $73 \%$ and $133 \%$, respectively. It worthy to mention that after addition of $3 \%$ SD to the soil there was a worst improvement of $\mathrm{K}_{\mathrm{s}}$, which help a quickly lose the irrigation water by deep percolation.

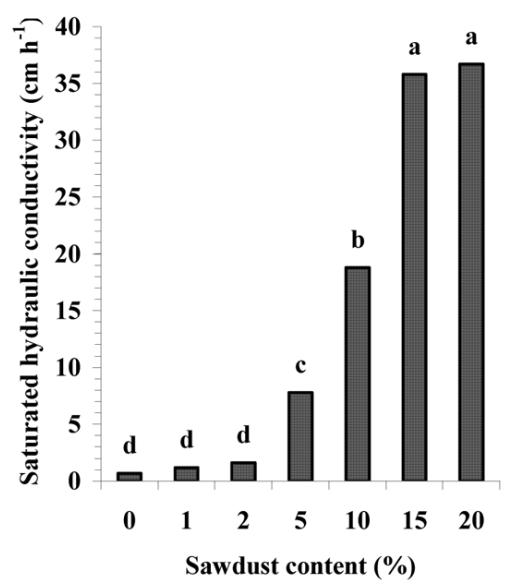

Bars with the same letter do not show significant differences for $(p \leq 0.05)$

Figure 1. Variation of saturated hydraulic conductivity $\left(\mathrm{K}_{\mathrm{s}}\right)$ with sawdust contents. 
The increase of Ks with the SD-amended soil treatments could be attributed to the presence of excess SD that would have changed the soil matrix (i.e., facilitated the cohesive interaction of soil/sawdust or sawdust/sawdust particles) resulted in increased the flocculation which led to increase void ratio and ultimately increase the coefficient of permeability. The sawdust potential to facilitate cohesive interaction of soil/sawdust particles was been indicated (Rajor et al., 1996). Also, sawdust potential to increase soil flocculation, and consequently, soil aggregation was been indicated (Ciroma et al., 2006; Eusufzai and Fujii, 2012; Edward, 2008). In addition, Eusufzai et al. (2007) indicated that application sawdust to clay loam soils in field experiment led to increase the nearsaturated hydraulic conductivity and he attributed to the reduction in solid phases of SD-amended soils and thus increase of the total porosity.

\subsection{Effects of sawdust on plasticity index and clay content parameters}

The variances of plasticity index (PI) and clay content based on the percentage of SD are illustrated in Figure 2. The results showed that the PI and clay content decreased significantly in all treatments from a maximum of $32.60 \%$ and $38 \%$ with the non-amended soil treatment to a minimum of $27.50 \%$ and $29.1 \%$ with the $20 \%$ SD-amended soil treatment, respectively. It's known that the main objective of stabilizing expansive soil is to reduce the plasticity index which is a sign of soil improvement. This is explained by the decrease in the clay particles content that contribute to plasticity by forming coarse-grained materials with larger surface areas; the increase of plasticity index with the increase of clay content was been indicated (Hugar and Soraganvi, 2014); this is on one hand. On the other hand, sawdust is considered low plastic material, which is decrease the plasticity index when it blends with the soil. Thus, the number of bonds between the clay particles is reduced with the increased sawdust/ clay particle bonds or sawdust/sawdust particle bonds. Due to this change in the consistency limits, soils blended with high percentage of SD changed from the high plasticity clay-loam group to the low plasticity clay-loam group. The sawdust potential to facilitate cohesive interaction of soil/sawdust particles was been indicated (Rajor et al., 1996). Even though the statistical analysis indicated a marked difference ( $P$ $\leq 0.05$ ) between the non-amended soil treatment and the other SD-amended soil treatments (Figure 2), however, there were no significant differences between the $2 \%, 5 \%, 10 \%, 15 \%$ and $20 \%$ SD-amended soil treatments. This is suggesting that optimum addition rate to improve the soil consistency was $2 \%$ sawdust.

\section{(a)}

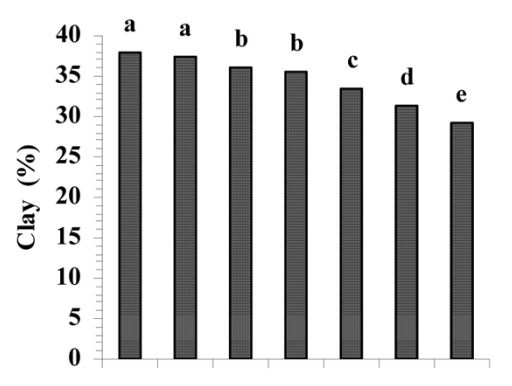

(b)

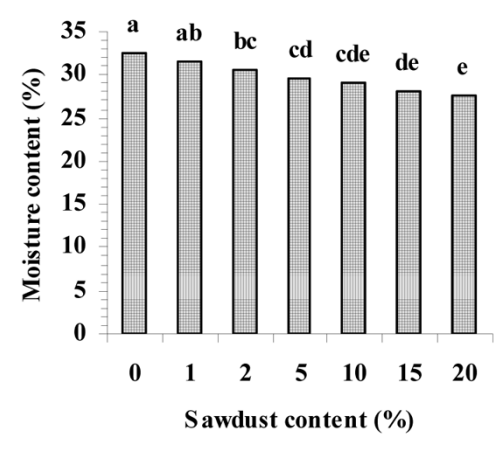

Bars with the same letter do not show significant differences for $(p \leq 0.05)$.

Figure 2. Variation of clay content (a) and plasticity index (b) with sawdust contents. 


\subsection{Effects of sawdust on the linear shrinkage}

The linear shrinkage (LS) variations between the SDamended soils treatments and the non-amended soil treatment are shown in Figure 3. The results indicated that the LS values slightly decreased with increasing sawdust content from $1 \%$ to $20 \%$. In the same trend, the addition of SD to a clay soil by $1 \%, 5 \%, 10 \%, 20 \%$ and $30 \%$ led to decrease the LS (Folaranmi, 2009). In addition, sawdust potential to improve linear shrinkage of expansive clay soil was been indicated (Manukaji, 2013). The results also indicated that the lowest values were reached with the $2 \%$, $5 \%, 10 \%, 15 \%$ and $20 \%$ SD-amended soil treatments. Although, statistically, the LS values of all SD-amended soil treatments after addition of $2 \%$ SD had no significant effect (Figure 3). This is suggesting that optimum addition rate to improve the soil shrinkage was $2 \%$ sawdust. These results given above can be interpreted with the fact of clay content decrease by adding mixtures of sawdust, which is normally inert material. Indeed, the mixture that has greater sawdust content reduces amplitude and shrinking pressure; this is on one hand. On the other hand, much of this shrinking is absorbed by the voids between coarse-

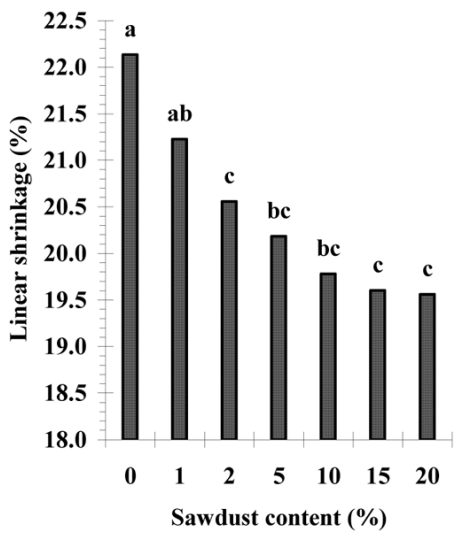

Bars with the same letter do not show significant differences for $(p \leq 0.05)$.

Figure 3. Variation of linear shrinkage (LS) with sawdust contents. grained materials formed due to sawdust/clay particle bonds or sawdust/sawdust particle bonds as illustrated above.

\subsection{Effects of sawdust on the desiccation crack development}

The SD was effective in reducing the amount of desiccation cracking that occurred in the non-amended soil treatment (the natural soil). In each sample, it was observed that the reduction in the development of desiccation cracks occurred with increasing SD content between $1 \%$ and $20 \%$. The cracks width decreased from $3 \mathrm{~mm}$ with the non-amended soil treatment to $0.1 \mathrm{~mm}$ with the $20 \%$ SD-amended soil treatment. Moreover, the addition of SD led to decrease the development of desiccation cracks and formation a network of small cracks with the $2 \%, 5 \%, 10 \%, 15 \%$ and $20 \%$ SDamended soil treatments compared to the non-amended soil treatment. On the other hand, statistically, the extent of development of desiccation cracks in samples containing SD higher than 10\% remained almost the same (Figure 4).

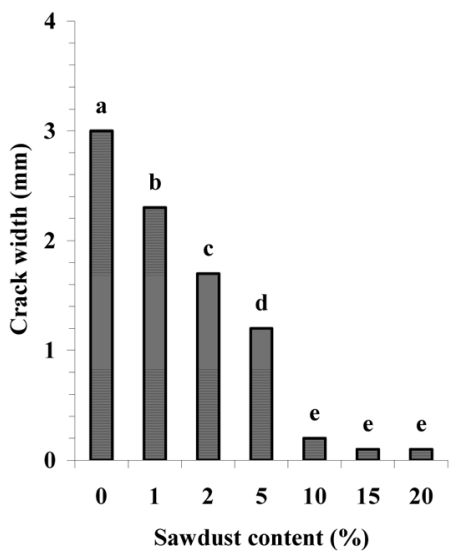

Bars with the same letter do not show significant differences for $(n<0.05)$

Figure 4. Variation of crack width $(\mathrm{CW})$ with sawdust contents 
The non-amended soil treatment has been cracked severely, whereas the SD-amended soil treatments suffered a little or no cracking. This could be because of the linear shrinkage strain, which occurs in the natural soils during desiccation, is direct function of the water/volume ratio of soil, when soil is saturated. It is known that the presence of high amounts of clay particles in the soil promotes the formation of cracks. Meanwhile, soils with higher clay content and higher plasticity indices, generally, have a greater volume of water, and thus are more prone to large linear shrinkage strain. However, the danger of shrinkage and cracking can be minimized by fortifying clay loam soil with coarse-grained materials. So, the fine sawdust has been used to minimize the effects of linear shrinkage strain of the clay loam soils through forming coarsegrained materials which it helps the soil-sawdust mixtures to display lower plasticity. For this reason, the development of desiccation cracks decreased on the surface of SD-amended soil treatments. Finally, it can be concluded that the modification of clay-loam soils by the sawdust waste material can be a viable and innovative method to reduce the development of desiccation cracks in the clay loam liner and cover systems. These findings reveal that, all other factors being equal, liner and cover systems constructed from the SD-amended soil treatments cracked less than liner and cover systems constructed from the natural clay loam soil.

\section{Conclusions}

Agricultural scientists have been reluctant to accept sawdust as a desirable form of organic matter to use as a mulch or soil amendment because of some of the problems it presents when added to the soil. However, in spite of these disadvantages, the benefits that are being derived from the use of these wood wastes in improving the hydro-physical properties of the soil for certain plants can not be overlooked. Therefore, in this study, the effects of fresh fine sawdust waste material on the hydro-physical properties of the middle
Nile Delta expansive soils was investigated and the following conclusions were drawn:

1. The hydraulic conductivity values highly increased with the increase additions of sawdust.

2. The plasticity index and the clay content decreased significantly in all treatments, which is a sign of soil physical properties improvement.

3. The additive mixtures played an important role in improving the problem shrinking behaviour of the expansive soils. The addition of sawdust to the expansive soil led to decrease the linear shrinking percentage.

4. The development of desiccation cracks decreased on the surface of the SD-amended soil treatments.

It can be concluded that sawdust had the potential to improve the hydro-physical properties of expansive soils, especially, when added into soil in between one to two percent on dry weight basis, above this percentage the improvement was much less significant and warranted by the clay content decrease. In addition, fine sawdust can be used to minimize the development of desiccation cracks and the shrinking behaviour of expansive soils. Moreover, the sawdust waste material can potentially reduce stabilization costs by utilizing waste in a cost-effective manner.

\section{References}

ASTM., 2000. American Society for Testing and Materials Annual Book of ASTM Standards, Vol. 4, Section 08 and 09, Construction Materials, Soils and Rocks: D 1452-80. West Conshohocken, Pennsylvania.

ASTM., 2005. American Society for Testing and Materials Annual Book of ASTM Standards, Vol. 4, Section 08 and 09, Construction Materials, Soils and Rocks: D 4318-05. West Conshohocken, Pennsylvania. 
Bashour, I.I., Sayegh, A.H. 2007. Methods of analysis for soils of arid and semi-arid regions. FAO, Rome, 35-38.

Chiroma, A.M., Folorunso, O.A., Alhassan, A.B. 2006. The effects of land configuration and woodshavings mulch on the properties of a sandy loam soil in northeast Nigeria. 2. Changes in physical properties. Tropicultura. 24 (1), 33-38.

Edward, M. 2008. Effect of saw dust on soil physical and chemical properties in Ntenjeru Sub country, Mukono District. Under Graduate Special Project Thesis, Makerere University, Kampala Uganda.

El Baroudy, A.A. 2011. Monitoring land degradation using remote sensing and GIS techniques in an area of the middle Nile Delta. Egypt. Catena, 87(2), 201-208.

Eusufzai, M.K., Fujii, K. 2012. Effect of Organic Matter Amendment on Hydraulic and Pore Characteristics of a Clay Loam Soil. Open Journal of Soil Science, 2, 372-381.

Eusufzai, M.K., Maeda, T., Fufii, K. 2007. Field evaluation of compost, sawdust and rice straw biomass on soil physical and hydraulic properties. Journal of the Japanese Society of Soil Physics. 107, 3-16.

Folaranmi, J. 2009. Effect of sawdust additive on the properties of clay. Australasian Journal of Technology. 13 (1), 53-56.
Haluschack, P. 2006. Particle size analysis (pipette method). In: Laboratory methods of analysis Canada-Manitoba soil survey. 12-24.

Hugar, G.M., Soraganvi, V.S. 2014. Impact of Soil Organic carbon on Bulk Density and plasticity index of Arid Soils of Raichur, India, International Research Journal of Environment Sciences, 3(2), 48-58.

Manukaji, J.U. 2013. The effects of sawdust addition on the insulating characteristics of clays from the federal capital territory of Abuja. International Journal of Engineering Research and Applications. 3 (2), 6-9.

Moustafa, M.M. 2000. A geostatistical approach to optimize the determination of saturated hydraulic conductivity for large-scale subsurface drainage design in Egypt. Agricultural Water Management. 42, 291-312.

Rajor, A., Sharma, R., Sood, V.K., Ramamurthy, V. 1996. A sawdust-derived soil conditioner promotes plant growth and improves waterholding capacity of different types of soils. Journal of Industrial Microbiology. 16 (4), 237-240. 